\title{
Lifestyle Changes for Abdominal Obesity Prevention and Encouraging Fruit Consumption May Be Beneficial in Preventing Left Ventricular Hypertrophy in Sub-Saharan African and Maghreb
}

\author{
Charifa Annis', Bernard Kianu Phanzu², Sidibe Moussa1, Mustapha El Hattaoui', \\ Benzaroual Dounia' ${ }^{1}$, Jean-René M'buyamba Kabangu ${ }^{2}$, Benjamin Longo-Mbenza ${ }^{3}$ \\ ${ }^{1}$ Cardiology Unit, CHU Mohammed VI, Marrakech, Kingdom of Morocco \\ ${ }^{2}$ Unit of Cardiology, University Hospital of Kinshasa, Kinshasa, Democratic Republic of Congo \\ ${ }^{3}$ Faculty of Health Sciences, Walter Sisulu University, Mthatha, Republic of South Africa \\ Email: doctorkianu@gmail.com
}

How to cite this paper: Annis, C., Phanzu, B.K., Moussa, S., El Hattaoui, M., Dounia, B., Kabangu, J.-R.M. and Longo-Mbenza, B. (2017) Lifestyle Changes for Abdominal Obesity Prevention and Encouraging Fruit Consumption May Be Beneficial in Preventing Left Ventricular Hypertrophy in Sub-Saharan African and Maghreb. World Journal of Cardiovascular Diseases, 7, 4656.

https://doi.org/10.4236/wjcd.2017.72005

Received: December 19, 2016

Accepted: February 21, 2017

Published: February 24, 2017

Copyright (๑) 2017 by authors and Scientific Research Publishing Inc. This work is licensed under the Creative Commons Attribution International License (CC BY 4.0).

http://creativecommons.org/licenses/by/4.0/ (c) $\underset{\mathrm{EY}}{ }$ Open Access

\begin{abstract}
There is a growing body of evidence showing a close correlation between left ventricular mass with cardiovascular morbidity and overall mortality. Therefore, identifying the determinants of left ventricular hypertrophy can be of great importance for cardiovascular prevention, for prognosis and therapeutic intervention. Objective: To assess the prevalence and identify the independent determinants of echocardiographic left ventricular hypertrophy in The MAGhreb and Sub-Saharan Africa Left-Ventricul ArGEometry Study (MAGSALVAGES) participants. Methods: The MAG-SALVAGES is a community based study in which 100 asymptomatic Black Sub-Saharan African (BSSA) and 189 white skin Maghreb within the age of 18 to 55 years underwent a resting echocardiography. Multivariate logistic regression analysis was utilized to identify the independent determinants of LVH left ventricular hypertrophy. Results: Men represented the majority of the enrolled participants: 173 (59.9\%). Echocardiographic left ventricular hypertrophy was seen in 10 (3.5\%) participants. Age $\geq 40$ years, female gender, overall obesity, abdominal obesity, hypertension status and less fruit consumption were significantly associated with echocardiography left ventricular hypertrophy. After adjusting for confounding factors, age $\geq 40$ years, female gender, abdominal obesity and less fruit consumption were independently and significantly associated with echocardiographic left ventricular hypertrophy, as illustrated in the following equation: $\mathrm{Y}=0.36+0.162$ age $>40$ years +2.69 female gender +2.52 abdominal
\end{abstract}


obesity +1.31 less fruit consumption. Conclusion: Lifestyle changes for the prevention of abdominal obesity and encouraging fruit consumption may be beneficial in preventing left ventricular hypertrophy.

\section{Keywords}

Left Ventricular Hypertrophy, Abdominal Obesity, Diet, Sub-Saharan African, Maghreb

\section{Introduction}

The period when the African continent was exempted from cardiovascular diseases (CVD) has long gone. Nowadays, Africa is among the most affected by these diseases worldwide [1]. There is a growing body of evidence showing a close correlation between left ventricular mass (LVM) with cardiovascular morbidity and overall mortality [2] [3]. Factors determining the LVM have been the focus of many investigations. The most cited are age and clinical parameters including systolic blood pressure, body size, and both visceral and free fat mass [4]. Nevertheless, most of these studies were carried out on non-African population and often focused on hypertensive population. LVM is determined by heritable genetic factors [5] as well as environmental factors [6] [7] [8]. These genetic and environmental factors influence the LVM either directly by promoting the synthesis of substances that act as agonists for receptor molecules involved in the pathogenesis of left ventricular hypertrophy (LVH) or via insulin resistance and/or other cardiovascular risk factors.

Identifying the determinants of left ventricular hypertrophy can be of great importance for the prevention of cardiovascular disease, for prognosis and therapeutic intervention.

Therefore, the aim of this study is to assess the prevalence and identify the independent determinants of echocardiographic LVH in The MAGhreb and SubSaharan Africa Left-VentriculAr GEometry Study (MAG-SALVAGES) participants.

\section{Methods}

The MAG-SALVAGES is a population-based survey conducted in Marrakech, Morocco, from November 2015 to January 2016. Black Sub-Saharan African (BSSA) and white skin Maghreb students living in Marrakech were randomly selected to participate in the survey.

\subsection{Recruitment Strategy}

Investigators: The investigation team consisted of senior residents of the Cardiology Unit of Cady Ayyad University. The principal investigators (CA and BKP) introduced the study, explained the goals, described how the study was to be performed, and described the responsibilities of each investigator. The principal 
investigators attended staff meetings to discuss and answer any questions the investigator team had. A pre-test session was conducted asking a dozen students to evaluate the questionnaire, to test the appropriateness of the data collection sheet, and to assess the ability of the investigators to apply the protocol correctly.

Study participants: the BSSA students was members of the CESAM (Confédération d'Etudiants et Stagiaires Africains de Marrakech), a cultural association that includes all BSSA students in Marrakech. The CESAM provided us with the names and addresses of BSSA students. Recruitment of Maghreb students was facilitated by the Secretary General of the Cady Ayyad University Students Office. Students were randomly chosen and invited to participate in the study.

Eligibility criteria: The subjects recruited for the MAG-SALVAGES were asymptomatic students aged 18 years or older, regardless of their level of study (undergraduate, graduate, post-graduate, or doctoral). Participants with significant valvulopathy, who had poor echogenicity to the extent that echocardiographic parameters could not be measured, or who did not complete the planned investigations were excluded.

\subsection{Data Collection}

\section{Interviews}

Participants were interviewed using a questionnaire in a 20-minute session. Items asked included demographic characteristics (sex, age, ethnic group, and duration of residence in Marrakech for BSSA), lifestyle (diet, physical activity, smoking status, and alcohol intake), and personal medical history (hypertension, diabetes mellitus (type 1 or type 2), hypercholesterolemia, and hyperuricemia). All these data were based on self-report. Participants were asked about their intake of fruits, vegetables, and fats, with regular consumption of fruits and vegetables defined as at least four days a week. Physical activity was assessed using the WHO/GPAQ [9]. The participants were categorized as either active or inactive based on whether they did or did not engage in moderate or vigorous exercise, with sedentary defined as sitting more than 7 hours daily. The categories for smoking were current smoker (defined as smoking at least one cigarette within the past month) or nonsmoker/former smoker (the latter defined as having quit smoking more than 3 month prior to the study). Alcohol consumption was categorized as excessive drinking ( $\geq 3$ units/day for men and $\geq 2$ units/day for women) or nondrinking/moderate drinking ( $\leq 2$ units/day for men and $\leq 1$ unit/day for women).

\subsection{Clinical Examination}

\subsubsection{Physical Measurements}

Participants were weighed without heavy clothing to the nearest $0.1 \mathrm{~kg}$ using a digital impedancemeter scale. The same apparatus also provided body composition (fat mass (\%), total body water (\%), lean body mass (\%), bone mass (kg), and daily energy expenditure (Kcal). Height was measured to the nearest $0.1 \mathrm{~cm}$ using a mounted stadiometer. Body mass index (BMI) was calculated as weight 
in kilograms (kg) divided by height in meters squared $\left(\mathrm{m}^{2}\right)$. És)dWaist circumference (WC) was measured using a flexible tape measure, with the participant standing, and after gentle expiration, at a point midway between the lower costal margin and the upper border of the iliac crest. Hip circumference was measured at the widest point of the buttocks. The waist-to-hip ratio (WHR) and the waistto-height ratio (WHeR) were calculated. Body surface area (BSA) was calculated $\mathrm{m}^{2}=0.007184 \times$ height $(\mathrm{cm}) 0.725 \times$ weight $(\mathrm{kg}) 0.425$. Total obesity was defined as a BMI greater than $30.0 \mathrm{~kg} / \mathrm{m}^{2}$ and abdominal obesity as WC $\geq 102 \mathrm{~cm}$ in males and $\geq 88 \mathrm{~cm}$ in females.

\subsubsection{Vital Signs}

Sitting blood pressure (BP) was measured on the upper left arm non-invasively using an automated validated device (OMRON M6, HEM 7001E) with a cuff size appropriate for the arm diameter. Participants relaxed for 5 minutes in a sitting position, after which the BP was measured twice. A third measurement was required if the first two differed by at least $10 \mathrm{mmHg}$ for systolic blood pressure (SBP) and/or $5 \mathrm{mmHg}$ for diastolic blood pressure (DBP). The BP readings were averaged for analysis. The BP monitors were calibrated every morning against a standard mercury sphygmomanometer using a T-tube and applying static pressures ranging from 0 to $250 \mathrm{mmHg}$ at $50-\mathrm{mmHg}$ intervals. A device that deviated by $5 \mathrm{mmHg}$ or more was replaced by a new one. Pulse pressure (PP) and mean arterial pressure (MAP) were calculated as follows: $\mathrm{PP}=\mathrm{SPB}-\mathrm{DBP}$; MAP $=\mathrm{DBP}+\mathrm{PP} / 3$.

The MAG-SALVAGES participants underwent a resting transthoracic echocardiography. Measurements were taken based on the 2015 American Society of Echocardiography and the European Association of Cardiovascular Imaging updated guidelines for cardiac chamber quantification [10]. The LVM was calculated based on the American Society of Echocardiography (ASE) simplified cubed equation "Linear Method" utilizing the following equation: LVM (grams) $=0.8 \times 1.04 \times[($ LVEDd + IVSd + LVPWd $) 3-$ LVEDd3 $]+0.6$ g. LVM was indexed by BSA and by height to the allometric power of $2.7\left(\mathrm{LVM} / \mathrm{HT}^{2.7}\right)$. LVM was considered as normal when $\leq 115 \mathrm{~g} / \mathrm{m}^{2}$ or $\leq 48 \mathrm{~g} / \mathrm{m}^{2.7}$ in male, $\leq 95 \mathrm{~g} / \mathrm{m}^{2}$ or $\leq$ $44 \mathrm{~g} / \mathrm{m}^{2.7}$ in female. LVH was defined by a LVM $>115 \mathrm{~g} / \mathrm{m}^{2}$ or $>48 \mathrm{~g} / \mathrm{m}^{2.7}$ in male, $>95 \mathrm{~g} / \mathrm{m}^{2}$ or $>44 \mathrm{~g} / \mathrm{m}^{2.7}$ in female. The LV relative wall thickness (RWT) was calculated utilizing the formula $(2 \times$ LVPWd $) /$ LVEDd. The RWT and its relationship with LVM were utilized to define LV geometric patterns. Four types of left ventricular geometric (LVG) patterns were then defined as follows: Normal geometry, normal LVM and RWT $\leq 0.42$; concentric remodeling, normal LVM and RWT $>0.42$; concentric hypertrophy, LVH and RWT $>0.42$ and eccentric hypertrophy, LVH and RWT $\leq 0.42$.

\subsubsection{Statistics}

The normal distribution of each variable was tested by Kolmogorov-Smirnov's test. Continuous data were expressed as means and standard deviations and were compared employing t-test. Categorical data were expressed as the frequencies 
and proportions of data in all subjects and were compared utilizing the chisquare test. One-way analysis of variance (ANOVA) with post hoc Duncan tests were applied to compare the differences among the groups. Calculating the odds ratio (OR) and confidence intervals at $95 \%$, the logistic regression analysis was used to assess the relative contribution of each factor to the risk of LVH. The probability value (p) less than $0.05(5 \%)$ was considered as the threshold of statistical significance. Multivariate logistic regression analysis was utilized to identify the independent determinants of LVH. The statistical analysis was carried out using SPSS, version 21, software (SPSS Inc., Chicago, IL, USA).

\section{Results}

A total of 302 participants were initially recruited, 102 BSSA and 200 Maghreb. Thirteen participants were excluded because of poor echogenicity (three female Maghreb), significant valvular disease (four female Maghreb), refusal to undergo the ECG and echocardiography for modesty reasons (two female Maghreb), and failure to appear for the echocardiography (two male BSSA and two male Maghreb). The final analysis therefore comprised 289 participants, 100 BSSA and 189 Maghreb. BSSA were from the following countries: Mali, Democratic Republic of the Congo, Congo-Brazzaville, Central African Republic, Cameroon, Togo, Chad, Zimbabwe, Tanzania, Angola, Sudan, Somalia, Madagascar, Mauritius, Comoros, Senegal, Nigeria, and Mauritania.

LVEDd was significantly higher among Maghreb than among BSSA, but this difference disappeared when indexed to BSA. LVPWd was significantly greater among BSSA than among Maghreb. This difference persisted after adjustment for confounding factors (BMI, WC, HR, and fat mass). The differences observed for all other echocardiographic parameters were not statistically significant, including LVM for which the means of the two groups were similar regardless of the mode of indexing (Table 1).

Table 1. Echocardiographic characteristics.

\begin{tabular}{ccccc}
\hline Variable & $\begin{array}{c}\text { All participants } \\
\mathrm{n}=289\end{array}$ & $\begin{array}{c}\text { BSSA } \\
\mathrm{n}=100\end{array}$ & $\begin{array}{c}\text { Maghreb } \\
\mathrm{n}=189\end{array}$ & $\mathrm{p}$ \\
\hline LVEDd $(\mathrm{mm})$ & $\mathbf{4 8 . 2} \pm 4.8$ & $\mathbf{4 7 . 1} \pm \mathbf{5 . 1}$ & $\mathbf{4 8 . 9} \pm 4.6$ & $\mathbf{0 . 0 0 4}$ \\
LVEDd/BS $\left(\mathrm{mm} / \mathrm{m}^{2}\right)$ & $25.6 \pm 6.0$ & $26.2 \pm 2.9$ & $25.3 \pm 7.2$ & 0.218 \\
LVEDs $(\mathrm{mm})$ & $30.3 \pm 4.1$ & $29.9 \pm 4.2$ & $30.6 \pm 4.1$ & 0.185 \\
LVPWd $(\mathrm{mm})$ & $\mathbf{8 . 1} \pm 1.3$ & $\mathbf{8 . 3} \pm 1.2$ & $\mathbf{7 . 9} \pm 1.3$ & 0.011 \\
IVSd $(\mathrm{mm})$ & $8.2 \pm 1.3$ & $8.4 \pm 1.3$ & $8.2 \pm 1.3$ & 0.187 \\
LVM $(\mathrm{g})$ & $133.7 \pm 36.1$ & $132.7 \pm 37.0$ & $134.2 \pm 35.7$ & 0.726 \\
LVM/height & $33.7 \pm 9.6$ & $32.1 \pm 9.8$ & $33.6 \pm 9.5$ & 0.185 \\
LVM/BS $\left(\mathrm{mg} / \mathrm{cm}^{2}\right)$ & $73.0 \pm 16.8$ & $73.1 \pm 17.8$ & $72.9 \pm 16.2$ & 0.922 \\
LVEF $(\%)$ & $65.7 \pm 7.7$ & $65.3 \pm 9.4$ & $65.9 \pm 6.6$ & 0.526 \\
\hline
\end{tabular}

BSSA: Black Sub-Saharan African, LVEDd: left ventricular end-diastolic diameter, LVEDd/BS: left ventricular end-diastolic diameter indexed for body surface area, LVEDs: left ventricular end-systolic diameter, LVPWd: left ventricular posterior wall thickness in diastole, IVSd: Interventricular septum thickness in diastole, LVM: left ventricular mass crude, LVM/height ${ }^{2.7}$ : left ventricular mass indexed for height 2.7 , LVM/BS: left ventricular mass indexed for body surface area, LVEF: left ventricular ejection fraction. 
According to Table 2, the different patterns of left ventricular geometry were equally distributed among the two ethnic groups.

From Table 3, it can be seen that the participants with LVH were older, more often female and obese than those without LVH. They had a higher SBP, MBP, with lower fruit consumption than those without LVH.

The main risk factors for LVH found are presented in Table 4. They include age over 40 years, female gender, overall obesity, abdominal obesity, systolic blood pressure, mean blood pressure, hypertension and low fruit consumption. After adjusting for confounding factors, only age $\geq 40$ years, female gender, abdominal obesity and low fruits consumption emerged as independent determinants of LVH.

\section{Discussion}

This study identified four determinants of LVH such as age, female gender, abdominal obesity and low fruits consumption.

Even if older age is associated with greater LVM and higher prevalence of LVH [11], the influence of age on LVM remain uncertain. It seems that not only age but all pathophysiologic abnormalities and various comorbidities associated with age are responsible for increasing the LVM in the elderly [12]. Indeed, ageing, in the absence of hypertension, is known to be associated with loss of arterial compliance, that induce geometric remodeling, leading to increased relative wall thickness without increase in overall LVM [13]. On the other hand, the LIFE study has shown that ageing do not attenuate the antihypertensive treatment related to the reduction of LVM [14].

The finding of female gender as a determinant of LVH is consistent with a recent Asian population based study, where women showed greater overall increase in LVM [11]. Female gender is usually considered a cardiovascular protective factor. This protection is linked to the beneficial effects of natural estrogen on lipid profile, insulin sensitivity and blood pressure. Nevertheless, the existence of a functional estrogen receptor in the ventricular myocardium suggests that estrogens could be double-edged knives which, beyond their protective effect, could affect the cellular physiology of cardiac tissues both genomically and nongenomically [15], leading to greater LVM.

Table 2. Left ventricular geometric patterns distribution

\begin{tabular}{ccccc}
\hline LVG patterns & $\begin{array}{c}\text { All participants } \\
\mathrm{n}=289\end{array}$ & $\begin{array}{c}\text { BSSA } \\
\mathrm{n}=100\end{array}$ & $\begin{array}{c}\text { Maghred } \\
\mathrm{n}=189\end{array}$ & $\mathrm{p}$ \\
\hline Normal geometry n (\%) & $157(54.3)$ & $83(83)$ & $74(39.1)$ & 0.781 \\
Concentric remodeling n (\%) & $122(42.2)$ & $17(17)$ & $105(55.5)$ & 0.607 \\
LVH n (\%) & $10(3.5)$ & $5(5)$ & $5(2.6)$ & 0.484 \\
Excentric LVH & $9(3.1)$ & $4(4)$ & $5(2.6)$ & \\
Concentric LVH & $1(0.3)$ & $1(1)$ & $0(0)$ & \\
\hline
\end{tabular}

LVG: left ventricular geometry, BSSA: Black Sub-Saharan African, LVH: left ventricular hypertrophy, BSSA: Black Sub-Saharan African. 
Table 3. Characteristics of the study population as a whole and stratified according to the presence or absence of LVH.

\begin{tabular}{|c|c|c|c|c|}
\hline Variables & $\begin{array}{c}\text { Whole group } \\
\mathrm{n}=289\end{array}$ & $\mathrm{LVH}+\mathrm{n}=10$ & $\mathrm{LVH}-\mathrm{n}=279$ & $\mathrm{p}$ \\
\hline Age, years & $29.8 \pm 11.2$ & $46.8 \pm 5.2$ & $29.2 \pm 10.9$ & $<0.0001$ \\
\hline Gender & & & & 0.001 \\
\hline Male & $173(59.9)$ & $1(10.0)$ & $172(61.6)$ & \\
\hline Female & $116(40.1)$ & $9(90.0)$ & $107(38.3)$ & \\
\hline HTN & $9(3.1)$ & $5(5.0)$ & $4(1.4)$ & 0.723 \\
\hline T1DM & $1(0.3)$ & $0(0.0)$ & $1(0.3)$ & 0.425 \\
\hline T2DM & $5(1.7)$ & $3(30.0)$ & $2(0.7)$ & 0.204 \\
\hline Dyslipidemia & $0(0.0)$ & $0(0.0)$ & $0(0.0)$ & \\
\hline Cigarette smoking & $18(6.2)$ & $1(10.0)$ & $17(6.1)$ & 0.453 \\
\hline Alcohol intake & $8(2.8)$ & $2(20.0)$ & $6(2.1)$ & 0.264 \\
\hline Fruit consumption & & & & 0.026 \\
\hline Low & $27(9.3)$ & $1(10.0)$ & $26(9.3)$ & \\
\hline Sufficient & $162(56.0)$ & $9(90)$ & $153(54.8)$ & \\
\hline Vegetables consumption & & & & 0.314 \\
\hline Low & $64(22.1)$ & $1(10.0)$ & $63(22.6)$ & \\
\hline Sufficient & $225(77.8)$ & $9(90.0)$ & $216(77.4)$ & \\
\hline $\begin{array}{l}\text { Physical activity of high } \\
\text { intensity at work }\end{array}$ & $14(4.8)$ & $2(20.0)$ & $12(4.3)$ & 0.078 \\
\hline Rides (10 min walk or bike) & $256(88.5)$ & $9(90.0)$ & $247(87.9)$ & 0.657 \\
\hline \multicolumn{5}{|l|}{$\begin{array}{l}\text { Time spent at sitting } \\
\text { position }\end{array}$} \\
\hline $1-4 h$ & $68(23.5)$ & $5(50.0)$ & $63(22.5)$ & 0.057 \\
\hline $5-9 h$ & $96(33.2)$ & $5(50.0)$ & $91(32.6)$ & 0.541 \\
\hline$\geq 10 \mathrm{~h}$ & $87(30.1)$ & $2(20.0)$ & $85(30.4)$ & 0.027 \\
\hline Weight, kg & $73.3 \pm 14.9$ & $85.1 \pm 0.92$ & $74.6 \pm 15.8$ & 0.351 \\
\hline Height, cm & $168.1 \pm 9.8$ & $165.2 \pm 5.5$ & $167.2 \pm 10.3$ & 0.023 \\
\hline BMI, $\mathrm{kg} / \mathrm{m}^{2}$ & $25.9 \pm 5.5$ & $30.7 \pm 4.9$ & $25.8 \pm 5.4$ & 0.006 \\
\hline $\mathrm{WC}, \mathrm{Cm}$ & $86.3 \pm 14.5$ & $99.2 \pm 11.3$ & $86.0 \pm 14.5$ & 0.005 \\
\hline WHiR & $0.87 \pm 0.12$ & $0.94 \pm 0.08$ & $0.86 \pm 0.12$ & 0.045 \\
\hline WHeR & $0.71 \pm 0.05$ & $0.62 \pm 0.07$ & $0.51 \pm 0.09$ & $<0.0001$ \\
\hline $\mathrm{SBP}, \mathrm{mmHg}$ & $119.4 \pm 15.1$ & $131.1 \pm 28.5$ & $119.0 \pm 14.3$ & 0.013 \\
\hline $\mathrm{DBP}, \mathrm{mmHg}$ & $77.2 \pm 10.1$ & $81.8 \pm 16.2$ & $77.1 \pm 9.9$ & 0.149 \\
\hline $\mathrm{MBP}, \mathrm{mmHg}$ & $91.3 \pm 10.7$ & $98.2 \pm 19.3$ & $91.1 \pm 10.2$ & 0.036 \\
\hline $\mathrm{PP}, \mathrm{mmHg}$ & $42.2 \pm 11.7$ & $49.3 \pm 17.8$ & $41.9 \pm 11.5$ & 0.051 \\
\hline Fat mass (\%) & $20.9 \pm 12.2$ & $23.4 \pm 12.4$ & $20.8 \pm 12.1$ & 0.526 \\
\hline Overall obesity & & & & 0.001 \\
\hline No & $226(78.2)$ & $3(1.3)$ & $223(98.6)$ & \\
\hline Yes & $63(21.8)$ & $7(11.1)$ & $56(88.8)$ & \\
\hline Abdominal obesity & & & & $<0.0001$ \\
\hline Yes & $64(22.1)$ & $8(12.5)$ & $56(87.5)$ & \\
\hline No & $225(77.8)$ & $2(0.9)$ & $224(99.5)$ & \\
\hline
\end{tabular}

LVH+: presence of left ventricular hypertrophy, LVH-: absence of left ventricular hypertrophy, HTN: hypertension, T1DM: type 1 diabetes mellitus, T2DM: type 2 diabetes mellitus. BMI: body mass index, WC: waist circumference, WHiR: waist-to-hip ratio, WHeR: waist-to-height ratio, SBP: systolic blood pressure, DBP: diastolic blood pressure, PP: pulse pressure, MBP: mean blood pressure, PP: pulse pressure. 
Table 4. Risk factor and determinants of LVH.

\begin{tabular}{|c|c|c|c|c|c|c|c|c|}
\hline \multirow[b]{2}{*}{ Variables } & \multicolumn{4}{|c|}{ Univariate analyses } & \multicolumn{4}{|c|}{ Multivariate analyses } \\
\hline & $\mathrm{p}$ & OR brut & IC $95 \%$ & & $\mathrm{p}$ & OR aj & IC $95 \%$ & \\
\hline \multicolumn{9}{|l|}{ Age } \\
\hline$\geq 40$ years & & 1 & & & & 1 & & \\
\hline$<40$ years & 0.010 & 0.865 & 0.799 & 0.936 & 0.005 & 0.850 & 0.760 & 0.952 \\
\hline \multicolumn{9}{|l|}{ Gender } \\
\hline Male & & 1 & & & & 1 & & \\
\hline Female & 0.012 & 14.417 & 1.801 & 115.388 & 0.037 & 14.736 & 1.169 & 185.839 \\
\hline \multicolumn{9}{|l|}{ Overall obesity } \\
\hline No & & 1 & & & & 1 & & \\
\hline Yes & 0.002 & 9.170 & 2.299 & 36.573 & 0.945 & 1.094 & 0.087 & 13.832 \\
\hline \multicolumn{9}{|c|}{ Abdominal obesity } \\
\hline No & & 1 & & & & 1 & & \\
\hline Yes & 0.001 & 15.719 & 3.249 & 76.052 & 0.021 & 12.535 & 1.244 & 64.220 \\
\hline SBP $\mathrm{mmHg}^{*}$ & 0.018 & 0.962 & 0.931 & 0.993 & 0.920 & 0.997 & 0.939 & 1.059 \\
\hline MBP mmHg* & 0.041 & 0.951 & 0.907 & 0.998 & 0.949 & 0.996 & 0.894 & 1.110 \\
\hline \multicolumn{9}{|l|}{ HTN } \\
\hline No & & 1 & & & & 1 & & \\
\hline Yes & 0.010 & 2.837 & 0.920 & 8.752 & 0.386 & 0.485 & 0.094 & 2.495 \\
\hline \multicolumn{9}{|c|}{ Fruit consumption } \\
\hline Sufficient & & 1 & & & & 1 & & \\
\hline Low & 0.002 & 7.316 & 0.915 & 58.522 & 0.030 & 3.707 & 1.308 & 44.663 \\
\hline
\end{tabular}

SBP: systolic blood pressure, MBP: mean blood pressure, HTN: hypertension.

Obesity is a risk factor for LVH [16] [17]. Moreover, since obesity and overweight are more common in black than in white [18], it has been postulated that body composition is the basis for the difference in prevalence of LVH between the two ethnic groups; but Mark et al. have demonstrated that this ethnic disparity on LVM persisted after adjustment for body composition [19]. However, on the other hand, the excess fat mass associated with abdominal obesity is known to cause hemodynamic changes which is thought to lead to a compensatory left ventricular hypertrophic response in response to increased wall stress [20] [21].

The finding of less fruit consumption being a determinant of LVH is in line with recent studies that have demonstrated that a diet rich in vegetables and fruit is associated with a low LVM [8]. Moreover, studies have suggested a dose-response effect of fruit and vegetable consumption on cardiovascular risk reduction [22].

Some studies found other determinants such as systolic, diastolic, and pulse pressures [11]. These parameters have not emerged as determinants of LVH in the present study, probably because participants of this study had normal blood pressure and where relatively young. 


\section{Study Limitations}

The main limitation of this study is the cross-sectional study design which limits observations of causal relationships among LVM and age, gender, AO and low fruit consumption.

\section{Conclusion}

The present study has identified four determinants of LVH, including two nonmodifiable factors that are age $\geq 40$ years and female gender and 2 modifiable factors that are $\mathrm{AO}$ and less fruit consumption. Lifestyle changes for abdominal obesity prevention and encouraging fruit consumption may be beneficial in preventing LVH. Interventional studies are needed to confirm this hypothesis.

\section{Author Contributions}

Design and concept of study: Annis Charifa. Acquisition of data: Kianu Phanzu Bernard, Annis Charifa, Sidibe Moussa; Manuscripti draft: Kianu Phanzu Bernard. Supervision: Kintoki Vita Eleuthère, Longo-Mbenza Benjamin, M' buyamba Kabangu, Benzaroual Dounia, El Hattaoui Mohammed. All authors read and approved the final manuscript.

\section{Acknowledgements}

The authors gratefully acknowledge Mr. CISSE Kalilou Papa, president of the CESAM and Mr. Sharif Zian, Secretary General of the Office of the Cady Ayyad University Students for their kindly facilitated the recruitment and mobilization of participants. The following people also accept the expression of gratitude to the authors of this work for their active and voluntary participation in the survey. These gentlemen Wetchi Adolphe, Louis Kyungu, Issa Imbongo, Harouna Mbaka and Djuma Nkubokoso. A special thanks is sent to the PAC Association (Physicians Accros Continents) through its Secretary General Dr. Saad Ali AlQarni for their partnership with the Faculty of Medicine of University of Kinshasa and for funding Dr Kianu Phanzu Bernard Training in the Service of Cardiology of CHU Mohammed VI of Marrakech. Are required to test this hypothesis.

\section{References}

[1] Moran, A., Forouzanfar, M., Sampson, U., Chugh, S., Feigin, V. and Mensah, G. (2013) The Epidemiology of Cardiovascular Diseases in Sub-Saharan Africa: The Global Burden of Diseases, Injuries and Risk Factors 2010 Study. Progress in Cardiovascular Diseases, 56, 234-239. https://doi.org/10.1016/j.pcad.2013.09.019

[2] Vakili, B.A., Okin, P.M. and Devereux, R.B. (2001) Prognostic Implications of Left Ventricular Hypertrophy. American Heart Journal, 141, 334-341. https://doi.org/10.1067/mhj.2001.113218

[3] Bluemke, D.A., Kronmal, R.A., Lima, J.A., Liu, K., Olson, J., Burke, G.L. and Folsom, A.R. (2008) The Relationship of Left Ventricular Mass and Geometry to Incident Cardiovascular Events. The MESA (Multi-Ethnic Study of Atherosclerosis) Study. Journal of the American College of Cardiology, 52, 8. 
https://doi.org/10.1016/j.jacc.2008.09.014

[4] Savage, D.D., Levy, D., Dannenberg, A.L., Garrison, R.J. and Castelli, W.P. (1990) Association of Echocardiographic Left Ventricular Mass with Body Size, Blood Pressure and Physical Activity (the Framingham Study). American Journal of Cardiology, 65, 371-376. https://doi.org/10.1016/0002-9149(90)90304-J

[5] Swan, L., Birnie, D.H., Padmanabhan, S., Inglis, G., Connell, J.M. and Hillis, W.S. (2003) The Genetic Determination of Left Ventricular Mass in Healthy Adults. European Heart Journal, 24, 6. https://doi.org/10.1016/S0195-668X(02)00524-9

[6] Pitsavos, C., Chrysohoou, C., Koutroumbi, M., Aggeli, C., Kourlaba, G., Panagiotakos, D., Michaelides, A. and Stefanadis, C. (2011) The Impact of Moderate Aerobic Physical Training on Left Ventricular Mass, Exercise Capacity and Blood Pressure Response during Treadmill Testing in Borderline and Mildly Hypertensive Males. Hellenic Journal of Cardiology, 52, 9.

[7] Nguyen, H.T., Bertoni, A.G., Nettleton, J.A., Bluemke, D.A., Levitan, E.B. and Burke, G.L. (2012) DASH Eating Pattern Is Associated with Favorable Left Ventricular Function in the Multi-Ethnic Study of Atherosclerosis. Journal of the American College of Nutrition, 31, 401-407. https://doi.org/10.1080/07315724.2012.10720466

[8] Gardener, H., Rundek, T., Wright, C.B., Gu, Y., Scarmeas, N., Homma, S., Russo, C., Elkind, M.S., Sacco, R.L. and Di Tullio, M.R. (2015) A Mediterranean-Style Diet and Left Ventricular Mass (from the Northern Manhattan Study). American Journal of Cardiology, 115, 5. https://doi.org/10.1016/j.amjcard.2014.11.038

[9] Cleland, C.L., Hunter, R.F., Kee, F., Cupples, M.E., Sallis, J.F. and Tully, M.A. (2014) Validity of the Global Physical Activity Questionnaire (GPAQ) in Assessing Levels and Change in Moderate-Vigorous Physical Activity and Sedentary Behaviour. BMC Public Health, 14, 1.

[10] Lang, R.M., Badano, L.P., Mor-Avi, V., Afilalo, J., Armstrong, A., Ernande, L., Flachskampf, F.A., Foster, E., Goldstein, S.A., Kuznetsova, T., Lancellotti, P., Muraru, D., Picard, M.H., Rietzschel, E.R., Rudski, L., Spencer, K.T., Tsang, W. and Voigt, J.U. (2015) Recommendations for Cardiac Chamber Quantification by Echocardiography in Adults: An Update from the American Society of Echocardiography and the European Association of Cardiovascular Imaging. Journal of the American Society of Echocardiography, 28, 39. https://doi.org/10.1016/j.echo.2014.10.003

[11] Chen, C., Sung, K.T., Shih, S.C., Liu, C.C., Kuo, J.Y., Hou, C.J., Hung, C.L. and Yeh, H.I. (2016) Age, Gender and Load-Related Influences on Left Ventricular Geometric Remodeling, Systolic Mid-Wall Function, and NTProBNP in Asymptomatic Asian Population. PLoS ONE, 11, e0156467.

https://doi.org/10.1371/journal.pone.0156467

[12] Gardin, J.M., Arnold, A., Gottdiener, J.S., Wong, N.D., Fried, L.P., Klopfenstein, H.S., O’Leary, D.H., Tracy, R. and Kronmal, R. (1997) Left Ventricular Mass in the Elderly. The Cardiovascular Health Study. Hypertension, 29, 1095-1103. https://doi.org/10.1161/01.HYP.29.5.1095

[13] Roman, M.J., Ganau, A., Saba, P.S., Pini, R., Pickering, T.G. and Devereux, R.B. (2000) Impact of Arterial Stiffening on Left Ventricular Structure. Hypertension, 36, 489-494. https://doi.org/10.1161/01.HYP.36.4.489

[14] Gerdts, E., Roman, M.J., Palmieri, V., Wachtell, K., Smith, G., Nieminen, M.S., Dahlöf, B. and Devereux, R.B. (2004) Impact of Age on Left Ventricular Hypertrophy Regression during Antihypertensive Treatment with Losartan or Atenolol (The LIFE Study). Journal of Human Hypertension, 18, 417-422. 
https://doi.org/10.1038/sj.jhh.1001718

[15] Mahmoodzadeh, S., Eder, S., Nordmeyer, J., Ehler, E., Huber, O., Martus, P., Weiske, J., Pregla, R., Hetzer, R. and Regitz-Zagrosek, V. (2006) Estrogen Receptor Alpha Up-Regulation and Redistribution in Human Heart Failure. FASEB Journal, 20, 926-934. https://doi.org/10.1096/fj.05-5148com

[16] Fox, E., Taylor, H., Andrew, M., Han, H., Mohamed, E., Garrison, R. and Skelton, T. (2004) Body Mass Index and Blood Pressure Influences on Left Ventricular Mass and Geometry in African Americans: The Atherosclerotic Risk in Communities (ARIC) Study. Hypertension, 44, 55-60. https://doi.org/10.1161/01.HYP.0000132373.26489.58

[17] De Simone, G., Palmieri, V., Bella, J.N., Celentano, A., Hong, Y., Oberman, A., Kitzman, D.W., Hopkins, P.N., Arnett, D.K. and Devereux, R.B. (2002) Association of Left Ventricular Hypertrophy with Metabolic Risk Factors: The HyperGEN Study. Journal of Hypertension, 20, 323-331. https://doi.org/10.1097/00004872-200202000-00024

[18] Statistical Fact Sheet 2013 Update. African Americans \& Cardiovascular Diseases. http://circ.ahajournals.org/lookup/doi/10.1161/CIR.0b013e31828124ad

[19] Drazner, M.H., Dries, D.L., Peshock, R.M., Cooper, R.S., Klassen, C., Kazi, F., Willett, D. and Victor, R.G. (2005) Left Ventricular Hypertrophy Is More Prevalent in Blacks than Whites in the General Population: The Dallas Heart Study. Hypertension, 46, 124-129. https://doi.org/10.1161/01.HYP.0000169972.96201.8e

[20] Alpert, M.A. (2001) Obesity Cardiomyopathy: Pathophysiology and Evolution of the Clinical Syndrome. American Journal of the Medical Sciences, 321, 225-236. https://doi.org/10.1097/00000441-200104000-00003

[21] Poirier, P., Giles, T.D., Bray, G.A., Hong, Y., Stern, J.S., Pi-Sunyer, F.X. and Eckel, R.H. (2006) Obesity and Cardiovascular Disease: Pathophysiology, Evaluation, and Effect of Weight Loss: An Update of the 1997 American Heart Association Scientific. Circulation, 113, 898-918. https://doi.org/10.1161/CIRCULATIONAHA.106.171016

[22] Liu, S., Manson, J.E., Lee, I.M., Cole, S.R., Hennekens, C.H., Willett, W.C. and Buring, J.E. (2000) Fruit and Vegetable Intake and Risk of Cardiovascular Disease: The Women's Health Study. American Journal of Clinical Nutrition, 72, 922-928.

\section{Scientific Research Publishing}

Submit or recommend next manuscript to SCIRP and we will provide best service for you:

Accepting pre-submission inquiries through Email, Facebook, LinkedIn, Twitter, etc. A wide selection of journals (inclusive of 9 subjects, more than 200 journals)

Providing 24-hour high-quality service

User-friendly online submission system

Fair and swift peer-review system

Efficient typesetting and proofreading procedure

Display of the result of downloads and visits, as well as the number of cited articles

Maximum dissemination of your research work

Submit your manuscript at: http://papersubmission.scirp.org/

Or contactwjcd@scirp.org 